\title{
Keberhasilan Petisi Pengesahan RUU Penghapusan Kekerasan Seksual terhadap Anak melalui Change.org
}

\section{Utin Kustriana $^{1}$}

${ }^{1}$ Prodi Ilmu Komunikasi, FISIP UHAMKA, Jl. Limau II, Kebayoran Baru, Jakarta Selatan, Indonesia, 12130

* Email Korespondensi: utinkustriana05@gmail.com

\begin{abstract}
A B S T R A K
Kata kunci: Change.org

Kekerasan

Perubahan

Petisi

Sosial

Change.org adalah situs petisi global yang juga tersedia dalam bahasa Indonesia. Melalui situs ini publik dapat menyusun petisi untuk mendorong perubahan sosial. Studi ini meneliti keberhasilan petisi untuk ratifikasi UU Penghapusan Kekerasan Seksual melalui Change.org. Peneliti menggunakan paradigma konstruktivisme dan teori determinisme teknologi. Teknik pengumpulan data dilakukan dengan wawancara mendalam dan studi literatur. Teknik analisis data dilakukan dengan analisis data kualitatif. Penelitian ini menemukan bahwa petisi untuk Rencana Penghapusan Kekerasan Seksual yang akan dihapus melalui situs web Change.org berhasil disahkan. Para penggagas petisi berhasil mengumpulkan sekitar 70 ribu pendukung, sehingga para pembuat keputusan menjadikannya pertimbangan penting. Untuk mendapatkan banyak dukungan, para penggagas petisi mendistribusikannya melalui email. Ia menggunakan kalimat yang sederhana dan jelas agar mudah dipahami. Dia juga menggunakan kalimat netral dan tidak menghakimi. Selain itu, para inisiator petisi menggunakan media lain untuk menjangkau sebanyak mungkin audiens, termasuk mereka yang tidak menggunakan media sosial. Kasus pelecehan seksual terhadap seorang siswa SMP di daerah Bengkulu oleh 14 remaja pada tahun 2016 menjadi faktor pendorong bagi banyak orang untuk mendukung petisi ini.
\end{abstract}

Keyword:

Keyword:
Change.org

Petition

Social change

Sexual

Violence

\section{A B S T R A C T}

Change.org is a global petition site which is also available in Indonesian. Through this site the public can compile a petition to encourage social change. This study examines the success of the petition for ratification of the Law on the Elimination of Sexual Violence through Change.org. Researchers use the constructivist paradigm and technological determinism theory. Data collection techniques carried out by in-depth interviews and literature study. Data analysis technique is done by qualitative data analysis. This research found that the petition for the Elimination of Sexual Violence Laws Plans to be abolished through the Change.org website was successfully passed. The initiators of the petition managed to gather around 70 thousand supporters, so the decision makers made it a significant consideration. To gain a lot of support, the initiators of the petition distributed it via e-mail. He uses simple and clear sentences to be easily understood. He also uses neutral and non-judgmental sentences. In addition, petition initiators use other media to reach as many audiences as possible, including those who do not use social media. The case of sexual harassment of a junior high school student in the Bengkulu area by 14 teenagers in 2016 became a motivating factor for many people to support this petition

\section{PENDAHULUAN}

Munculnya Internet memungkinkan komunikasi tidak selalu harus dilakukan secara tatap muka atau melalui media massa, melainkan bisa juga melalui media sosial. Kehadiran Internet membawa perubahan besar dalam kehidupan manusia, terutama dalam hal berkomunikasi. Dalam masyarakat informasi (information society) orang semakin dibingkai oleh teknologi informasi dan komunikasi. Jika dulu masyarakat perkotaan tidak saling mengenal, dengan munculnya Internet keadaan menjadi berubah. Orang-orang yang tidak saling mengenal bisa "bertemu" dan berkenalan melalui media sosial.

Internet menjadi suatu media berita baru pada Januari 1998 saat Matt Drudge menggunakan situs web untuk mengumumkan bahwa majalah Newsweek telah menyembunyikan berita tentang keterlibatan Presiden Clinton dengan Monica Lewinsky di 
Gedung Putih. Menurut beberapa ahli, laporan Drudge ini telah melambungkan nama Internet, seperti halnya laporan CNN saat Perang Teluk yang menaikkan nama televisi ini (Severin dan Tankard, 2011).

Salah satu hasil dari teknologi Internet adalah situs Change.org yang menyediakan sarana untuk menyampaikan petisi terhadap suatu permasalahan yang dianggap merugikan masyarakat. Di situs ini semua orang dari bagian dunia mana pun dapat memulai berkampanye, menggerakkan pendukung, dan saling bekerja sama untuk mencari solusi terhadap suatu permasalahan. Melalui situs ini pula penggagas petisi dapat memeroleh belasan hingga puluhan ribu tanda tangan dari anggota masyarakat yang mendukung suatu isu yang diusulkan untuk dilaksanakan. Melalui petisi daring ini masyarakat dapat melakukan suatu perubahan sosial. Menurut Soemardjan (2009), perubahan sosial adalah perubahan yang terjadi pada lembaga kemasyarakatan di dalam suatu masyarakat yang mempengaruhi ssstem sosialnya.

Situs Change.org mulai muncul pada 2007. Situs ini merupakan gagasan Benjamin Michael Rattray di California, Amerika Serikat. Benjamin mendirikan situs ini sebagai sarana potensial untuk suatu gerakan perubahan. Meski awalnya merupakan situs oleh jejaring sosial lokal guna memerhatikan masalahmasalah sosial setempat, namun lama kelamaan situs ini berkembang menjadi sarana petisi daring dengan cakupan yang lebih luas. Di negara asalnya, situs ini memberi pengaruh yang besar terhadap perubahan sosial dan politik.

Secara global situs ini diperkenalkan sejak 2012. Dengan cepat situs ini tersebar ke berbagai negara dan menggunakan berbagai bahasa, selain bahasa Inggris. Change.org juga membuka kantor perwakilan di Indonesia yang dikendalikan empat orang, yaitu Usman Hamid, Arief Aziz, Dhenok Pratiwi, dan Desmarita Murni. Sejak itu berbagai permasalahan diangkat dalam situs ini untuk mencari dukungan dan berhasil. Sebuah petisi akan cepat memperoleh dukungan dari banyak orang jika memiliki tiga pertanyaan kunci: apa yang dapat saya coba ubah?, siapa yang bisa membuat suatu perubahan?, dan mengapa hal ini penting untuk diubah?

Petisi-petisi daring yang memeroleh kemenangan antara lain petisi John Muhammad agar kasus Abraham Samad dan Bambang Wijoyanto dari Komisi Pemberantasan Korupsi (KPK) dihentikan. Juga petisi A. Setiawan Abadi yang mendesak agar Ketua Dewan Perwakilan Rakyat (DPR), Setyo Novanto mundur sebagai Ketua DPR, karena terlibat korupsi e-KTP.

Parlemen Jerman mulai memperkenalkan petisi elektronik kepada publik pada 2005. Petisi ini dikirimkan, ditandatangani, dan didiskusikan di Internet. Dua tahun kemudian Lindner dan Reihm menyurvei terhadap 571 petisioner tradisional dan 350 petisi elektronik untuk melihat karakteristik mereka. Hasilnya menunjukkan bahwa kedua kelompok petisioner adalah mereka yang partisipasi politiknya di atas ratarata dan mereka adalah pengguna Internet. Pengguna petisi elektronik memiliki usia yang lebih muda daripada yang tradisional. Petisioner elektronik laki-laki lebih dominan dan umumnya mereka memiliki tingkat pendidikan yang lebih tinggi daripada yang tradisional. Petisi elektronik seperti menggaungkan ketidaksetaraan dalam pola partispasi, karena pesertanya adalah orang yang secara individu tertarik untuk aktif pada politik dan memiliki pendidikan dan sosial ekonomi yang lebih tinggi. Hal ini tidak seimbang dengan petisioner yang tradisonal.

Di Indonesia, penelitian mengenai petisi melalui media baru, seperti Twitter pernah dilakukan Putri (2012). Ia meneliti tentang Peran Media Baru dalam Membentuk Gerakan Sosial, studi kasus terhadap individu yang terlibat dalam IndonesiaUnite di Twitter. Hasil penelitian ini menunjukkan bahwa IndonesiaUnite mampu menimbulkan rasa kebersamaan dalam kelompok, sehingga melekatkan groupthink syndrome yang positif. Twitter memiliki kekuatan besar untuk membentuk suatu gerakan sosial.

Petisi yang ramai diusulkan di Change.org adalah disahkannya UndangUndang Penghapusan Kekerasan Seksual. Petisi yang diawali oleh Lentera Sintas Indonesia ini mengajukan petisi kepada Komisi VII DPR RI, Menteri Pemberdayaan Perempuan dan Perlindungan Anak, serta Presiden Joko Widodo. Rancangan Undang-Undang (RUU) Penghapusan Kekerasan Seksual hingga saat itu belum mendapat perhatian dari DPR maupun pemerintah. Padahal RUU ini penting karena memberikan payung hukum untuk melindungi 
korban kekerasan seksual. UU yang ada sebelumnya tidak sempurna karena belum berpihak pada korban perkosaan. UU ini masih menganggap tindak kekerasan seksual sebatas sebagai masalah asusila dan bukan masalah kejahatan kemanusiaan.

Menurut catatan Komisi Nasional Antikekerasan terhadap Perempuan Perempuan (Komnas Perempuan) pada 2015, setiap hari ada 35 perempuan di Indonesia yang mengalami kekerasan seksual. Ini berarti setiap dua jam terdapat tiga orang perempuan yang mengalami kekerasan seksual. Kekerasan terhadap perempuan tidak hanya dilakukan secara verbal, fisik, dan emosional, tetapi juga kekerasan seksual.

Sejak 2012, Indonesia tergolong darurat kekerasan seksual. Komisi Perlindungan Anak Indonesia (KPAI) mencatat terdapat 21.689.987 aduan pelanggaran hak anak yang tersebar di 33 provinsi dan 202 kabupaten/kota selama lima tahun terakhir (sejak 2011). Dari angka tersebut $58 \%$ di antaranya adalah kejahatan sesksual.

Penelitian ini mengkaji mengenai peran Change.org sebagai sarana perubahan sosial masyarakat di dalam meloloskan RUU Penghapusan Kekerasan Seksual terhadap Anak.

\section{METODE PENELITIAN}

Penelitian ini menggunakan pendekatan kualitatif dan jenis penelitian deskriptif. Pendekatan kualitatif bertujuan menjelaskan fenomena dengan sedalam-dalamnya melalui pengumpulan data yang sedalam-dalamnya pula. Dalam pendekatan ini yang lebih ditekankan adalah persoalan kedalaman (kualitas) data (Kriyantono, 2009). Penelitian kualitatif memberikan keleluasaan kepada peneliti dalam mengembangkan proses-proses mental yang terjadi antara peneliti dan objek penelitian. Fenomena yang terjadi memerlukan proses-proses mental peneliti untuk memaknainya.

Metode penelitian adalah studi kasus. Studi kasus merupakan metode riset yang menggunakan berbagai sumber data yang bisa digunakan untuk meneliti, menguraikan, dan menjelaskan secara komprehensif berbagai aspek individu, kelompok, suatu program, organisasi atau peristiwa secara sistematis (Kriyantono, 2009). Menurut Yin (2015), studi kasus merupakan inkuiri empiris yang menyelidiki fenomena di dalam konteks kehidupan nyata. Sebagai suatu inkuiri studi kasus tidak harus dilakukan dalam waktu yang lama dan tidak pula harus tergantung pada data etnografi atau observasi partisipan. Untuk memahami mengenai penggunaan situs web Change.org guna menyebarkan suatu petisi peneliti lebih bnyak mempertanyakan mengapa dan bagaimana. Studi kasus yang digunakan adalah studi analisis situasional, karena mengarah pada kejadian-kejadian sosial tertentu yang sedang berlangsung,

Pengumpulan data dilakukan dengan observasi nonpastisipan, wawancara mendalam, dan studi dokumentasi. Penelitian dilakukan selama tiga bulan, terhitung sejak SeptemberNovember 2016. Analisis data dilakukan dengan analisis data kualitatif. Peneliti mereduksi data, memilih hal-hal yang pokok, lalu memfokuskan pada hal yang penting untuk mencari tema dan polanya.

\section{HASIL DAN PEMBAHASAN}

Sebagai situs pengusul perubahan, Change.org memiliki visi mewadahi siapa pun untuk memulai, bergabung, dan memenangkan kampanye-kampanye sosial. Misinya, memberdayakan siapa saja, di mana pun untuk mampu membuat perubahan di sekitarnya.

Situs Change.org sama seperti media sosial, seperti Facebook, Twitter, dan YouTube. Perbedaannya, situs ini memfokuskan pada konten petisi. Jadi, siapa pun dapat memulai mengusulkan suatu petisi, seperti Save KPK. Untuk memulai suatu petisi, pertama kita harus log in pada situs Change.org. Kemudian, klik opsi untuk memulai petisi. Tulis judul petisi. Judul hendaknya singkat dan fokus pada perubahan yang dikehendaki. Selanjutnya, menentukan pengambil keputusaan, apakah individu, kelompok, atau organisasi. Tahap selanjutnya adalah menjelaskan masalah yang ingin diselesaikan dan bagaimana perubahan yang diusulkan berdampak pada masyarakat. Terakhir, sebarkan petisi ini untuk mendapatkan dukungan sebanyak mungkin. Untuk itu, pengusul dapat menyebarkan melalui e-mail atau media sosial lainnya.

Sejak dibuka pada awal Juni 2012, situs yang tersedia dalam bahasa Indonesia ini telah berhasil meloloskan 40 petisi untuk 
diwujudkan. Sasaran petisi ini tidak hanya kepada pemerintah, tetapi juga ke pihak swasta, seperti pengusaha atau perusahaan. Ketika pada 2016 terjadi pemerkosaan terhadap seorang siswa SMP oleh 14 pemuda di Bengkulu, Lentera Sintas Indonesia bersama majalah daring Magdalene mengawali petisi melalui Change.org agar DPR segera mengesahkan RUU Penghapusan Kekerasan Seksual terhadap Anak.

\section{Keberhasilan Petisi RUU Penghapusan Kekerasan Seksual terhadap Anak melalui Change.org}

Salah satu indikator keberhasilan sebuah petisi di Change.org adalah banyaknya jumlah orang yang ikut menandatangani petisi. Untuk bisa memperoleh dukungan sebanyakbanyaknya, pengusul awal petisi menyampaikan pesannya dengan bahasa yang jelas, berusaha membujuk sasaran, dan tidak menyudutkan pihak tertentu. Seperti dijelaskan Wulan Danoekoesoemo ${ }^{1}$, Direktur Eksekutif Lentera Sintas Indonesia,

"Kami selalu mengimbau publik agar bersuara dengan mengatakan, kejahatan terjadi karena banyak orang baik bersikap diam. Dengan imbauan ini kami ingin menyadarkan mereka untuk bersuara. Kami berusaha menggunakan bahasa yang sederhana dan ramah, serta tidak menyudutkan salah satu pihak. Dengan cara seperti ini kami berharap banyak pihak yang bersimpati dan ikut menandatangani petisi. Semakin banyak orang yang berperanserta, semakin besar sumber kekuatan kami dalam mengajukan petisi."

Wulan menjelaskan, "Kami berhasil berhasil menjangkau 35 ribu netizen dalam waktu 24 jam. Jumlah ini sekira 30\% dari keseluruhan responden. Dari angka ini sudah kelihatan secara kuantitas petisi ini mendapat dukungan dari banyak pihak. Penandatangan petisi mulai melambat pada saat angka mencapai 75 ribu pendukung. Untuk terus mendorong kenaikannya kami mengundang figure publik, seperti Dian Sastrowardoyo dan Chiko Jerikho untuk ikut serta."

\footnotetext{
${ }^{1}$ Wawancara pada 25 Oktober 2016 di Jakarta.
}

Selain mengumpulkan jumlah penandatangan, Wulan juga melakukan survei daring untuk memotret fenomena kekerasan seksual di Indonesia. "Bisa jadi ada kasus kekerasan yang belum dilaporkan. Kami akan ikut mengadvokasi," lanjut Wulan.

Setelah jumlah penandatangan mencapai angka 75 ribu lebih selama tiga bulan, pihak Lentera Sintas Indonesia dibantu Komnas Perempuan mengirimkan petisi kepada Ketua Komisi VIII DPR, Saleh Daulay, Sekretaris Kabinet RI, Pramono Anung, dan Menteri Sosial, Khofifah Indarparawansa. Akhirnya, RUU PKS berhasil menjadi prioritas pembahasan oleh Legislatif dalam Prolegnas 2016.

Wulan mengakui, petisi melalui Change.org bukan satu-satunya faktor yang menentukan keberhasilan. "Agar lebih efektif, kami juga harus melakukan kampanye di media sosial agar mendapat dukungan sebanyak mungkin dari masyarakat. Bisa juga dengan cara lain, seperti pemberian informasi seperti getok tular (word mouth campaign)," kata Wulan.

Desmarita Murni $^{2}$, Direktur Komunikasi Change.org, mengatakan bahwa lembaganya memfasilitasi siapa saja yang memiliki keresahan terhadap suatu isu sosial tertentu.

"Change.org merupakan platform terbuka yang siapa pun bisa menggunakannya. Platform platform global ini sudah mengantarkan banyak petisi untuk diperhatikan dan dikabulkan oleh pengambil kebijakan. Sebagai admin, kami menekankan bahwa petisi yang diunggah di situs kami hendaknya memiliki tujuan yang jelas dan jelas pula sasarannya. Jika petisi berhasil, sebetulnya bukan Change.org yang hebat. Kami hanya membuat aturan dan memastikan kontenkonten yang ada tidak mengandung unsur kekerasan, diskriminasi, tidak melanggar hukum dan tidak mengintimidasi, atau membully," ujar Desmarita.

Tokoh dan pengamat pers, Atmakusumah Astraatmadja ${ }^{3}$ menanggapi positif keberadaan Change.org.

\footnotetext{
${ }^{2}$ Wawancara pada 28 Oktober 2016 di Jakarta.

${ }^{3}$ Diwawancara pada 3 November 2016 di Jakarta.
} 
"Masyarakat dapat menggunakan media apa pun untuk menyampaikan aspirasinya. Baik itu melalui media massa, seperti suratkabar, radio, dan televisi maupun media sosial lainnya. Change.org dikelola dengan baik dan profesional. Kendati demikian, sebaiknya petisi yang diunggah juga disebarluaskan melalui media konvensional agar masyarakat yang tidak bisa mengakses situs ini bisa mendukung petisi yang sedang diajukan," ujar Atmakusumah seraya mengingatkan bahwa penggunaan Internet di Indonesia belum merata.

Desmarita menyadari keterbatasan sebagian masyarakat untuk mengakses situs ini.

"Kami menggunakan media sosial yang lebih mudah dijangkau, seperti Twitter. Pendukung petisi bisa langsung mention di Twitternya. Selain itu kami juga melakukan pengumpulan tanda tangan secara langsung dari masyarakat. Kami memahami adanya keengganan masyarakat berpartisipasi dalam petisi di Change.org. Salah satunya karena ketakutan mereka terkena Undang-Undang ITE. Misalnya, takut dianggap mencemarkan nama baik orang atau lembaga yang dipetisi," kata Desmarita yang menjamin keamanan konten-konten di dalam situsnya.

Meski menghadapi beberapa kendala di atas, namun $\mathrm{Siti}^{4}$, seorang mahasiswa UI yang sering ikut menandatangani petisi merasakan manfaat situs ini. "Change.org sangat membantu masyarakat yang menghendaki adanya suatu perubahan," ujar gadis yang pernah ikut menandatangi petisi stop penjualan gading gajah di toko daring. Petisi ini banyak yang mendukung dan berhasil menghentikan penjualan gading.

\section{Keberhasilan Petisi Sahkan RUU PKS sebagai sarana Perubahan Sosial Masyarakat}

Perkembangan teknologi komunikasi yang pesat sangat bermanfaat bagi masyarakat. Hadirnya situs Change.org, misalnya, dapat memfasilitasi masyarakat untuk mengajukan

\footnotetext{
${ }^{4}$ Diwawancara pada 2 November 2016 di Jakarta.
}

petisi mengenai hal-hal yang dianggap merugikan masyarakat. Sebaliknya, dukungan masyarakat terhadap petisi yang diajukan dapat memperkuat tuntutan, sehingga pengambil kebijakan akan memperhatikan dan mempertimbangkannya.

"Jumlah pendukung petisi RUU PKS yang mencapai 83.055 orang, sangat berpengaruh. Kendati demikian, pihak Change.org tetap harus terus mengawal sejauh mana petisi tersebut sampai dan dipertimbangkan oleh pengambil kebijakan. Lembaga ini tetap harus melihat perjuangan para pembela Hak Azazi Manusia yang selama bertahun-tahun tak lelahlelahnya berjuang," ungkap Atmakusumah.

Wulan mengakui bahwa perjalanannya untuk mewujudkan UU yang pro pada korban pelecehan seksual tidak mudah. Ini berkaitan dengan budaya patriarkhi masyarakat Indonesia. Budaya ini beranggapan bahwa dalam kejadian pelecehan seksual yang selalu salah adalah pihak korban (perempuan). Karena itu Wulan memandang Peraturan Pemerintah Pengganti Undang-Undang soal Pelecehan seksual masih terlalu lemah untuk melindungi korban.

"Konsentrasinya justru masih pada pelaku tetapi tidak memperhatikan kesejahteraan korban. Ini yang perlu kita dorong agar berubah. Selama ini jika terjadi pelecehan seksual yang salah selalu perempuan sebagai korban. Kalau korbannya anak kecil atau bayi dan kejadiannya di rumah sendiri dan pelakunya adalah keluarga, apakah masih juga korban yang salah?" tegas Wulan.

Setiap kali pendukung menandatangani petisi, e-mailnya secara otomatis terkirim langsung pada pihak yang menjadi sasaran, seperti DPR atau pejabat pemerintah. Jika pendukungnya sudah mencapai puluhan ribu, maka mereka akan mendapat e-mail dari sekian puluh ribu orang. "Saya kira mereka akan sulit mengabaikan pesan-pesan tersebut," kata Desmarita.

Change.org memanfaatkan Internet untuk menyebarkan petisi-petisinya agar mendapat dukungan dari masyarakat dan menyampaikannya pada pihak yang berkepentingan. Pemanfaatan Internet untuk menyampaikan petisi ini sesuai dengan teori determinisme teknologi yang digagas oleh Marshal McLuhan (dalam Nurudin, 2007). Teori ini berasumsi bahwa perubahan yang terjadi pada cara berkomunikasi manusia akan 
membentuk perubahan pada kehidupan manusia.

Menurut McLuhan (1994), budaya dibentuk oleh bagaimana cara kita berkomunikasi. Ada beberapa tahapan pembentukan budaya oleh komunikasi. Pertama, penemuan teknologi komunikasi yang menyebabkan perubahan budaya. Kedua, perubahan di dalam jenis-jenis komunikasi akhirnya membentuk kehidupan manusia. Dengan kata lain McLuhan menyimpulkan bahwa media adalah pesan itu sendiri (medium is the message). Inilah yang dimaksud bahwa media lebih penting daripada isi pesan yang disampaikannya.

Dalam bukunya Understanding Media, McLuhan mengemukakan bahwa teknologi komunikasi memainkan peran penting dalam tatanan sosial budaya, Internet yang merupakan suatu jaringan yang menghubungkan setiap komputer yang ada di dunia membentuk suatu global village. Media baru dapat menyatukan semua media lama, karena semua tulisan, suara, gambar, dan video dapat disatukan dalam satu platform.

Griffin (2003) mengatakan bahwa nothing remains untouched by communication technology. Ini mirip dengan yang dikatakan oleh McLuhan bahwa media massa adalah kepanjangan tangan dari manusia (the extension of man). Media tidak hanya memperpanjang jangkauan kita terhadap suatu tempat, peristiwa, atau informasi tetapi juga menjadikan hidup menjadi lebih efisien. Lebih dari itu media membantu kita dalam menafsirkan tentang kehidupan kita.

Dalam konteks penelitian ini, media seperti situs Change.org mampu memperkuat, menyuarakan, dan memperluas keinginan orang untuk memperjuangkan RUU PKS yang cenderung pro pelaku pemerkosaan, untuk disahkan sebagai Undang-Undang yang prokorban. Di Indonesia yang situasinya sudah pada darurat kekerasan seksual pada anak kehadiran situs Change.org sangat bermanfaat untuk mengubah keadaan menjadi lebih baik.

\section{Kesimpulan}

Dengan adanya Internet muncul media baru, seperti situ Change.org. Media ini memfasilitasi masyarakat untuk menyuarakan pendapatnya melalui suatu petisi. Salah satunya adalah petisi untuk mengesahkan RUU Penghapusan Kekerasan Seksual. Melalui petisi ini masyarakat didorong untuk ikut menandatanganinya. Petisi ini berhasil mendapatkan tanda tangan dari 83.055 orang. Keberhasilan ini terjadi karena beberapa hal:

Penggagas petisi menggunakan e-mail untuk menyebarkan petisinya. Setiap orang yang membalas email, yang berarti menyetujui, akan tersambung pada pihak-pihak yang berwenang, seperti Presiden RI, Djoko Wododo, Komisi VIII DPR RI, dan Menteri Pemberdayaan Perempuan dan Perlindungan Anak. Dengan demkian para pengambil keputusan mengetahui jumlah orang yang mendukung petisi ini.

Petisi ini menggunakan kalimat yang sederhana dan jelas, sehingga mudah dipahami. Juga menggunakan kalimat yang netral dan tidak bersifat menghakimi salah satu pihak, sehingga bisa menarik simpati.

Penggagas petisi selain menggunakan $e$ mail, juga memanfaatkan media sosial lain, seperti Twitter sehingga dapat menjangkau sebanyak mungkin khalayak.

Kasus pelecehan seksual terhadap siswi SMP di Kabupaten Bengkulu oleh 14 remaja menjadi faktor pendorong simpati khalayak untuk mendukung petisi ini.

\section{References}

Griffin, EM. 2003. 2009. A First Look at Communication Theory. New York: McGrawHill.

Kriyantono, Rachmat. 2010. Teknik Praktis Riset Komunikasi. Jakarta: Kencana. Prenada Media Grup.

Lindner, Ralf dan Ulrich Riehm. 2012. Broadening Participation through E-Petitions? An Empirical Study of Petitions to German Parliament. http://doi.org/10.2202/1944-2866.1083.

McLuhan, Marshall. 1994. Understanding Media. The Extension of Man. USA: The MIT Press.

Nurudin. 2007. Pengantar Komunikasi Massa. Jakarta: Raja Grafindo Persada.

Pambayun, Ellys Lestari. 2013. One Stop Qualitative Research Methodology in Communication. Jakarta: Lentera Printing.

Putri, Dibyareswari Putri. 2012. Depok: Universitas Indonesia, Skripsi, tidak diterbitkan.

Severin, Werner J dan James W. Tankard, Jr. 2005. Teori Komunikasi, Sejarah, Metode dan Terapan di dalam Media Mass. (Edisi Terjemahan). Jakarta: Kencana. 
Komunika: Jurnal Ilmu Komunikasi

Soemardjan, Selo. 2009. Perubahan Sosial di Yin, Robert K. 2015. Studi Kasus. Desain dan Yogyakarta. Jakarta: Komunitas Bambu. Metode. Jakarta: Rajawali Press.

Sztompka, Piotr. 2010. Sosiologi Perubahan Sosial.

Jakarta: Prenada. bawah syarat dan ketentuan Creative Commons Attribution (CC-BY) license (http://creativecommons.org/licenses/by/4.0/). 